\title{
ESTUDO DE PROSPECÇÃO DO CONCRETO VERDE
}

\author{
Victor Ranieri Bomfim Sampaio de Araújo*; Sílvia Beatriz Beger Uchôa; Patricia Brandão Barbosa \\ da Silva; Thais Gama Lins de Araújo; Elaine Aroxa Pereira Galhoz Florentino
}

\begin{abstract}
Núcleo de Inovação Tecnológica; PROPEP, Universidade Federal de Alagoas, Av. Lourival Melo Mota, s/n, Cidade Universitária, Maceió, AL, Brasil, CEP: 57072-900 (ranieri.victor@gmail.com)
\end{abstract}

\section{RESUMO}

Este artigo foi elaborado com foco nos problemas gerados pelo uso intensivo do concreto armado pelo setor da construção civil e como o setor está procurando inovações para a diminuição dos impactos econômicos e ambientais. Procurou-se a definição de concreto verde, ou mesmo um concreto ecológico, como uma forma de minimizar os impactos produzidos pelo uso das matérias primas e da emissão de gases para a atmosfera durante a fabricação do cimento. Dessa forma, buscou-se patentes envolvendo o uso de resíduos incorporados ao concreto e que substituíssem parte do cimento. Foram encontrados poucos documentos mostrando que o setor ainda não despertou para esse grave problema e, mais ainda, documentos de patente que não chegaram a ser concedidos, mostrando o pouco interesse dos fabricantes. Espera-se que haja um crescimento na busca desses concretos verdes no futuro próximo.

Palavras-chave: concreto verde; sustentabilidade; aproveitamento de resíduos

\begin{abstract}
This article was developed focused on the problems generated by the intensive use of reinforced concrete by the construction industry and how the industry was looking for innovations to reduce the economic and environmental impacts of this material. Green concrete, or ecological concrete, was used as the way to minimize the impacts produced by the use of raw materials and the emission of gases into the atmosphere during the manufacture of cement. Thus, it was searched patents involving the use of waste incorporated into the concrete and to replace part of the cement. Some documents were found, showing that the sector has not yet aware to this serious problem, and further, that there are patent documents that did not came to be granted, showing little interest from manufacturers. It is expected that there will have a growth in the use of green concrete in the near future.
\end{abstract}

Key words: green concrete; sustainability; waste using

Área tecnológica: Materiais

Cadernos de Prospecção - ISSN 1983-1358 (print) 2317-0026 (online), 2013, vol.6, n.2, p.106-114.

D.O.I.: http://dx.doi.org/10.9771/S.CPROSP.2013.002.013 


\section{DESCRIÇÃO DA TECNOLOGIA}

Desde a década de 60, o tema sustentabilidade tem sido debatido. Com o objetivo principal de preservar o meio ambiente, foram elaborados documentos, como o Relatório de Bruntland: Nosso Futuro Comum da década de 80; a Declaração do Rio, Agenda 21 nos anos noventa. Dando continuidade a essas discussões, teve-se recentemente a Conferência das Nações Unidas sobre Desenvolvimento Sustentável, conhecida como Rio+20, por marcar os 20 anos de realização desta mesma conferência em 1992, que contribuiu para definir a agenda do desenvolvimento sustentável das décadas que se seguiriam (CONFERÊNCIA DAS NAÇÕES UNIDAS SOBRE DESENVOLVIMENTO SUSTENTÁVEL, 2012). Tal ação teve como objetivo regulamentar as questões relacionadas ao meio ambiente, tratando da utilização consciente das matérias-primas não renováveis e sua substituição por renováveis, assegurando assim a conservação do planeta.

Nesse sentido, a sustentabilidade deve ser buscada em todas as áreas, sendo uma delas a construção civil, pois segundo Enercorn empowering environment (2012), as atividades da construção civil em todo o mundo consomem 3 bilhões de toneladas de matérias-primas a cada ano. Isso representa $40 \%$ do uso global das matérias-primas. Afirma ainda que o uso de materiais verdes na construção diminui a utilização de recursos não renováveis em escala global.

Atualmente, já existem certificações criadas para construções sustentáveis, como a americana Leadership in Energy and Environment Designa - LEED e a Alta Qualidade Ambiental AQUA. Entre outros aspectos, essas certificações se fundamentam: no princípio da eficiência energética e no uso racional de água e qualidade ambiental interna da edificação. Tem-se ainda o conselho Brasileiro de Construção Sustentável - CDBS, que tem como objetivo induzir o setor da construção a utilizar práticas mais sustentáveis, melhorando a qualidade de vida dos usuários, dos trabalhadores e do entorno das edificações. O CBDS é composto por diversos comitês que tratam de assuntos específicos relacionados à sustentabilidade no setor, como materiais e finanças.

O sistema de construção civil é composto por várias etapas, implicando em uma variedade de materiais utilizados. Dentro desse sistema têm-se um elemento fundamental que é o concreto, material construtivo mais consumido no mundo, abrangendo desde as edificações mais simples até estruturas de grande complexidade e dimensões. Esse fato se deve, dentre outros aspectos, à sua moldabilidade quando no estado fresco e a sua alta resistência quando no estado endurecido. Além disso, apresenta baixo custo e, ao contrário do aço e da madeira, apresenta uma menor deterioração quando exposto à água (MEHTA, 2008).

Justamente pelo seu grande consumo, o concreto tem sido foco de inúmeras pesquisas científicas por todo o mundo. Um dos fatores que o coloca em foco, nas discussões relacionadas à sustentabilidade na construção civil, é que o concreto utiliza em sua composição tradicional o cimento, que é responsável pela emissão de 90\% do gás carbônico (GOVERNO DE ALAGOAS, 2012).

Dentro da construção civil, outro problema ambiental são os resíduos gerados, também chamados de entulhos. Os resíduos de construção e demolição não tem seu volume conhecido, bem como muitas vezes os impactos ambientais também não são medidos, além do desconhecimento das possibilidades de seu reaproveitamento (PINTO, 2000).

Não somente na construção civil há acúmulo de resíduos, nas mais diversas indústrias são gerados dos os mais diversos resíduos. Muitas empresas fazem o descarte de maneira incorreta, mas muitas 
também fazem o descarte correto, mas o que mais beneficia o meio ambiente é sua reutilização. Esta além de não descartar os resíduos, mesmo que seja de maneira correta, ainda economiza outras matérias primas e consegue diminuir os custos das obras.

Segundo a Enercorn Empowering Environment (2012) concreto verde é aquele que utilizando produtos de resíduos gerados por indústrias em várias formas, como escória de alto forno, cinzas de casca de arroz e sílica ativa, poupa o meio ambiente. O seu uso ajuda na economia de energia, diminui as emissões de gases e resíduos do próprio concreto, além da economia de água. Também é mais barato que o concreto tradicional (ISAIA et al., 2004). Outra vantagem é a integração do chamado material verde dentro da construção, o qual ajuda a reduzir os impactos ambientais associados à extração, transporte, processamento, fabricação, instalação, reutilização, reciclagem e descarte desses materiais de construção de origem da indústria.

Também chamado de concreto sustentável, tal concreto não é apenas bom para o meio ambiente, mas beneficia as instalações, pois aumenta a vida útil do concreto e melhora suas características, o que faz dele uma opção economicamente mais viável para a construção civil. Deve-se atentar que este material apresenta resistência mecânica superior a 20 MegaPascal, mínimo estabelecido pela norma brasileira de concreto. Outro fator ambiental é a substituição de parte do cimento por resíduos, pois como dito o cimento é o principal responsável pela emissão de gás carbônico. (GOVERNO DE ALAGOAS, 2012).

Sendo assim, define-se como concreto verde aquele que utiliza resíduos, tanto da construção civil como de outras indústrias, substituindo parte do cimento por um resíduo. A definição da quantidade exata de substituição ainda leva a controvérsias, mas nesse trabalho buscou-se avaliar se já há preocupação com esse material, grande consumidor de matéria prima mundial.

\section{METODOLOGIA OU ESCOPO}

O presente estudo tem como objetivo fazer a prospecção tecnológica do chamado Concreto Verde. Para tal, foi feita uma revisão bibliográfica do que é tal concreto, para poder assim definir as palavras-chaves a serem utilizadas no mapeamento.

Para se fazer uma prospeç̧ão é preciso primeiro fazer o mapeamento, identificando o estado da técnica e o cenário do desenvolvimento das tecnologias. Após o mapeamento, é possível fazer a prospecção, que é o exercício de produzir visões de futuro, identificar oportunidades e ameaças, tendências e prioridades (CENTRO DE GESTÃO E ESTUDOS ESTRATÉGICOS, 2005).

As buscas para o mapeamento foram feitas na base de dados do Instituto Nacional da Propriedade Industrial. Primeiramente, foi feita a busca pelos principais compostos que poderiam substituir o cimento, como a sílica ativa, e depois foram utilizados termos mais abrangentes como concreto ecológico.

Foram feitas então as buscas utilizando as seguintes palavras-chave no resumo: "concreto and sílica”, "concreto and microssílica”, "concreto and escória and alto-forno”, "concreto and cinza and casca and arroz”, "concreto and resíduos”, "concreto and ecológico” e "concreto and verde”. Foram obtidas um total de 111 patentes pesquisadas.

Os dados foram tabulados no software de planilha eletrônica, no qual também foram tratados os dados e feitos os gráficos. Quanto à definição de concreto verde, foi visto que é aquele que se 
utiliza de resíduos e que consegue diminuir a utilização de cimento, principal emissor de gás carbônico. Das 21 patentes selecionadas apenas 02 cumpriam estes dois pré-requisitos, chamadas assim de concreto verde tipo "A”, e 19 patentes se utilizavam apenas dos resíduos, chamadas de concreto verde tipo "B".

\section{RESULTADOS E DISCUSSÃO}

Foram encontradas muitas patentes que utilizavam sílica, microssílica, escória de alto-forno e cinza de casca de arroz, mas que não utilizavam resíduos nem diminuíam a quantidade de cimento, sendo utilizados apenas para melhorar as características do concreto, mas sem focar nas questões ambientais.

Na segunda parte das buscas, com os termos resíduos, ecológico e verde, foram encontradas 21 patentes, que são aqui trabalhadas. Concreto and Ecológico resultou em 4 patentes, sendo 3 do tipo "B" e 1 do "A" e Concreto and Resíduos resultou em 17, sendo 1 do tipo “A” e 16 do tipo "B".

Segue primeiro a análise somente do concreto verde tipo “B”.

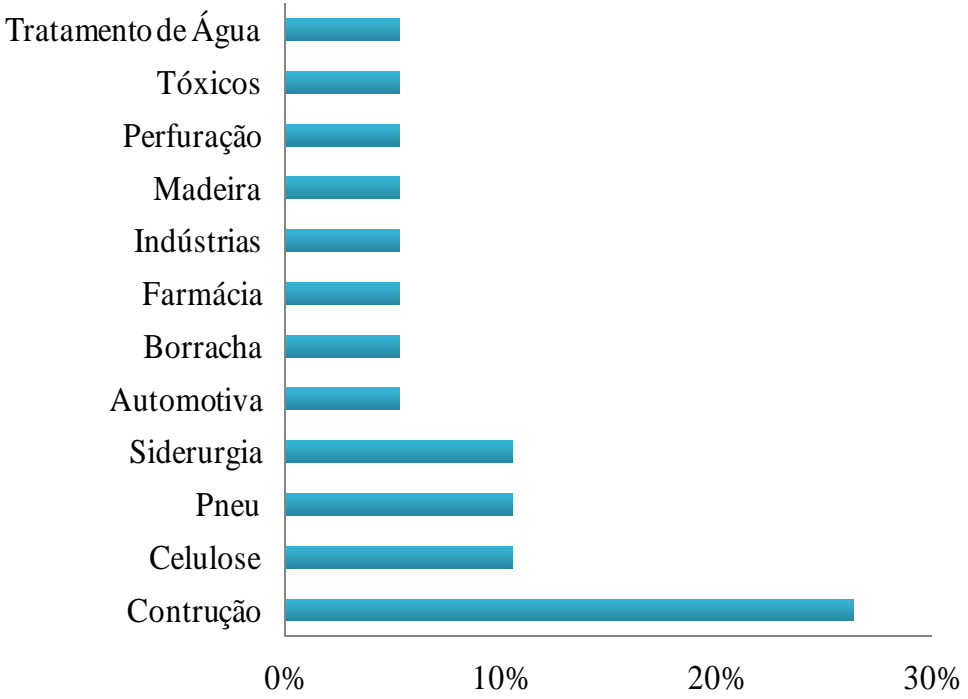

Figura 1: Setores onde são coletados os resíduos do concreto ecológico tipo B. Fonte: Autoria própria, 2012.

Pode-se observar que o setor onde há maior coleta é o próprio setor da construção. Pode-se afirmar que a comodidade de se captar tal resíduo e a própria composição, que eram resíduos do próprio concreto ou de materiais que podem ser facilmente adicionados à produção do mesmo, influencia neste resultado. Outros setores que se destacam são siderurgia, celulose e pneu. No setor de siderurgia, já há um dos resíduos, a escória de alto forno que é correntemente utilizada na fabricação de dois tipos de cimento Portland. 
Tabela 1: Uso de resíduos do setor por estado e região.

\begin{tabular}{l|c|c}
\hline \multicolumn{1}{c|}{ Resíduos } & Estado & Região \\
\hline Automotivo & PR & Sul \\
\hline Borracha & SP & Sudeste \\
\hline Celulose & ES, SP & Sudeste \\
\hline Construção & MG, PR, SP, MG & Sul/Sudeste \\
\hline Farmácia & PR & Sul \\
\hline Indústrias como um todo & RJ & Sudeste \\
\hline Madeira & BA & Nordeste \\
\hline Perfuração & RJ & Sudeste \\
\hline Pneu & MG, RJ & Sudeste \\
\hline Siderurgia & PR, MG & Sul/Sudeste \\
\hline Tóxicos & SC & Sul \\
\hline Tratamento de Água & PR & Sul \\
\hline Font: Autra propra 2012 & &
\end{tabular}

Fonte: Autoria própria, 2012.

A Tabela 1 demonstra os estados e regiões onde foram registradas as patentes por setor de coleta de resíduos, ficando evidente a supremacia das regiões Sul e Sudeste, que se deve ao estado de desenvolvimento industrial destas regiões. Ressalta-se que a construção civil vem crescendo em todo o país, além de ser um dos setores subsidiados pelo Governo Federal, através principalmente de programas de incentivo, mas fica claro que nas outras regiões há o predomínio das técnicas tradicionais.

Para ter uma melhor visão desta distribuição, tem-se a Figura 2.

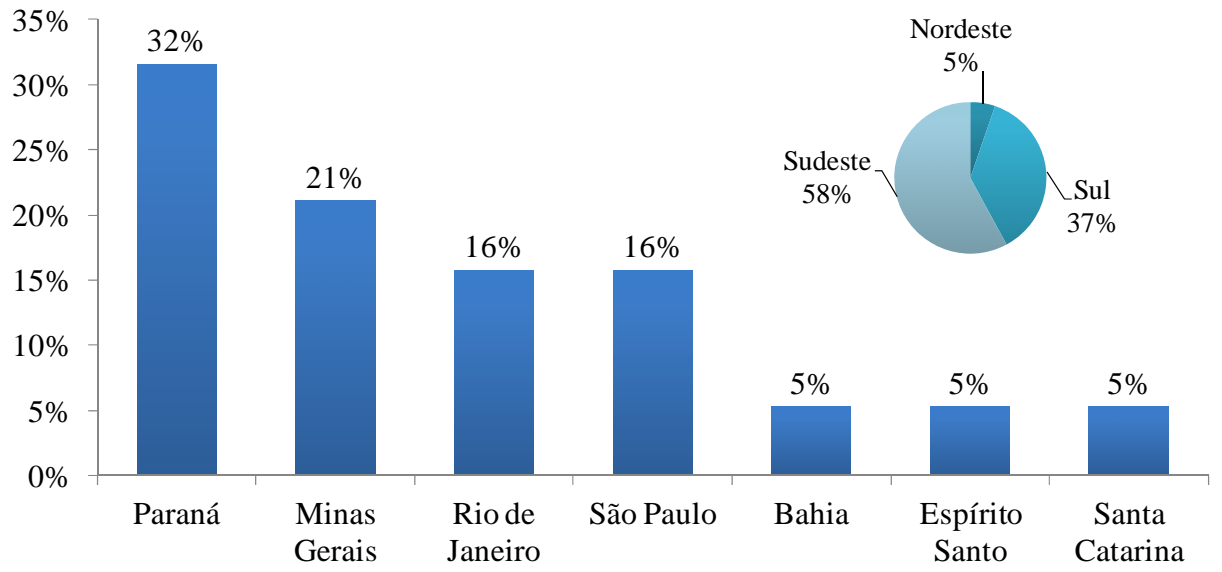

Figura 2: Estado / Região das patentes depositadas. Fonte: Autoria própria, 2012. 
Fica evidente que o Sul e Sudeste predominam no registro destas tecnologias, o Nordeste, representado pela Bahia, teve apenas uma patente depositada e o Sudeste predomina com quase $60 \%$ das patentes, o que é explicado também pelo desenvolvimento das regiões.

Na análise do Concreto Tipo “A” foram encontradas duas patentes que tratam deste tipo de concreto. Uma no estado de São Paulo, que encontra-se publicada, foi depositada em 2004 e permite a diminuição de até $30 \%$ do cimento. A outra foi depositada no Rio Grande do Norte, em 2006 e apesar de permitir a diminuição de até 50\% do cimento, tal patente encontra-se arquivada.

Fica evidente que tal tecnologia é mais recente que a do concreto verde tipo "B”, cuja primeira patente é de 1993. Já na análise das regiões, o pequeno número de patentes encontradas não permite tirar conclusões.

A primeira patente é de 1993, mesmo com as discussões ambientais no Brasil terem começado na década de 60. Pode se destacar que as preocupações ambientais ficaram mais evidentes nesse setor e teve-se o começo das ações concretas após a Conferência das Nações Unidas sobre Desenvolvimento Sustentável no Rio de Janeiro em 1992, como exemplifica a análise dos depósitos por ano.

Nota-se um crescimento considerável nos anos 2000, tal fato pode ser explicado pela situação econômica e financeira do Brasil, que por esta época se estabilizou e proporcionou um crescimento sólido.

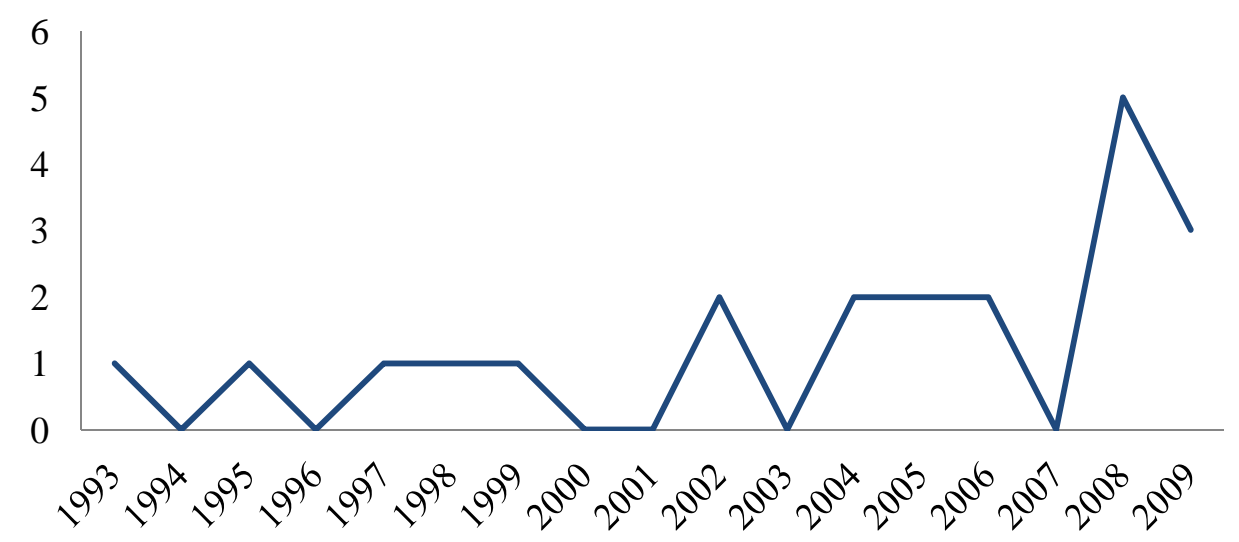

Figura 3: Depósitos por ano. Fonte: Autoria própria, 2012.

Como citado na metodologia, primeiramente foi feita uma busca utilizando os nomes dos compostos que poderiam ser adicionados ao concreto, para diminuir a quantidade de cimento empregada, mas não foi encontrada nenhuma patente que fizesse tal adição para substituir o cimento. Já na busca com termos mais abrangentes só se teve resultado com estes dois termos. 


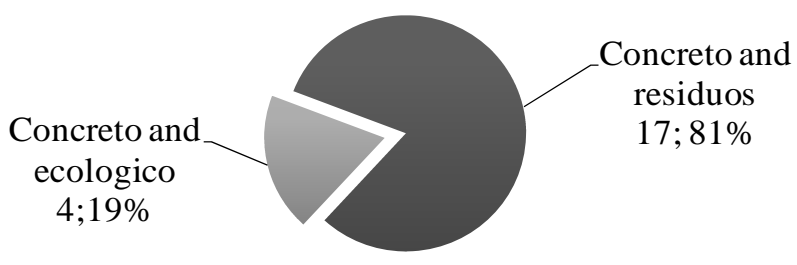

Figura 4: Patentes encontradas por palavra-chave. Fonte: Autoria própria, 2012.

Já no que diz respeito ao estado em que se encontram os depósitos, deve-se atentar ao baixo número de indeferimentos e o grande número de arquivamentos. Os baixos indeferimentos mostram que os depositantes dominam a técnica e os documentos não encontram inconsistência, mas o grande número de arquivamentos mostra que as patentes não chegam a ser concedidas, ressaltando o desinteresse dos fabricantes. Mas com o constante aumento da preocupação pelo meio ambiente, espera-se que tal quadro mude.

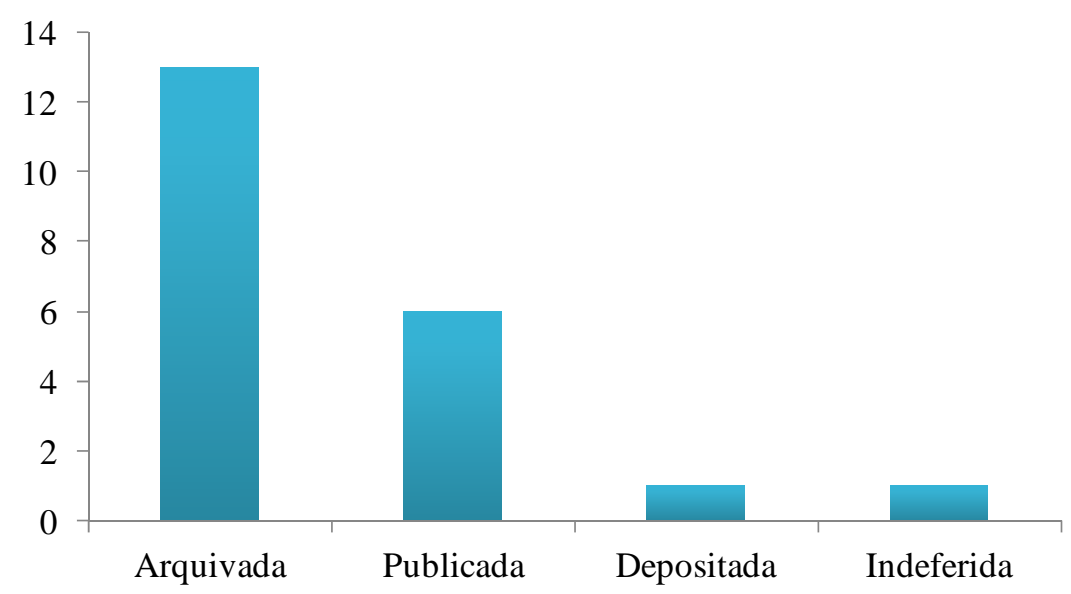

Figura 5: Situação do documento. Fonte: Autoria própria, 2012.

A prospecção possibilita que o processo de inovação seja mais seguro e adequado às necessidades do indivíduo ou da organização, possibilitando a redução de riscos e incertezas e fazendo com que a inovação seja mais atrativa e vantajosa, através do fornecimento de informações estratégicas.

A primeira Conferência das Nações Unidas sobre Desenvolvimento Sustentável em 1992 foi um fator que impulsionou as patentes relacionadas ao concreto verde, como já mencionado. Neste ano de 2012 ocorreu a segunda edição, conhecida como Rio + 20, por ser exatamente 20 anos após a primeira. Espera-se assim que os depósitos relacionados a esta área continuem a aumentar. Mas 
espera-se que a distribuição por região seja alterada, principalmente pelo crescimento das regiões Norte e Nordeste.

Outro fator que impulsiona o crescimento desta tecnologia são os chamados "selos verdes”. Tais selos identificam as empresas que possuem uma preocupação ambiental. Sendo o comportamento dos consumidores, que passam a exigir ou preferir as empresas que possuem estes selos, outro fator para impulsionar o crescimento desta tecnologia. Com isto, espera-se que as patentes do concreto verde tipo “A” venha a crescer mais do que as do tipo "B”, por causa da preocupação em relação à emissão de gás carbônico.

Destaca-se também a utilização dos resíduos dos pneus, pois já em 2003 Fioriti e Akasaki destacaram o aumento do número de veículos e que tal aumento gera o descarte do pneu. Sendo a indústria automotiva e a da construção civil dois carros chefes das políticas de crescimento do Governo Federal, ressaltando aqui a diminuição do Imposto sobre Produtos Industrializados - IPI para os veículos e o programa Minha Casa Minha Vida. O primeiro incentiva a comercialização de veículos, o que gera um aumento significativo do descarte de pneus, e o segundo promove o incentivo a aquisição de imóveis, gerando uma grande demanda para a construção civil.

\section{CONCLUSÃO}

Tem-se que o grande vilão da indústria do concreto é o cimento, responsável por 90\% de emissões de gás carbônico. Em contra partida a esta grande emissão, o concreto tem a capacidade de absorver resíduos de diversas áreas, inclusive os do próprio concreto, reduzindo o impacto ambiental, ao substituir o descarte.

Pode-se concluir que hoje as Regiões Sudeste e Sul são as que mais depositam patentes relacionadas ao concreto verde, mas com base na prospecção é esperado que as região Norte e Nordeste, principalmente a segunda, que aparece com apenas 10\% dos depósitos, venham a alcançar um patamar de destaque.

Espera-se ainda que as patentes que tratam do concreto verde que diminui a emissão direta de gás carbônico venham a crescer, mais do que as que se utilizam somente de resíduos, sem diminuir a quantidade de consumo de cimento.

\section{REFERÊNCIAS}

ALVES, A. P. OS DIVERSOS TIPOS DE VAREJO. Disponível em: <http://www.blogdojj.com.br/2011/08/21/os-diversos-tipos-de-varejo/>. Acesso em: 25 out. 2012.

CGEE - CENTRO DE GESTÃO E ESTUDOS ESTRATÉGICOS. Glossário. Disponível em: < http://www.cgee.org.br/prospeccao/index.php?operacao=Exibir\&serv=textos/topicos/texto_exib\&tt o_id=5\&tex_id=1>. Acesso em: 15 out. 2012.

CONFERENCIA DAS NAÇÕES UNIDAS SOBRE DESENVOLVIMENTO SUSTENTÁVEL, RIO+20, 2012, Rio de Janeiro. Sobre a Rio+20. Rio de janeiro: 2012. Disponível em: <http://www.rio20.gov.br/sobre_a_rio_mais_20.html>. Acessado em: 18 out. 2012. 
ENERCORN EMPOWERING ENVIRONMENT (Índia). Green Concrete. Disponível em: <http://www.greenconcreteonline.com/contactus.aspx>. Acessado em: 18 out. 2012.

FIORITI, C. F.; AKASAKI, J. L. Fabricação de blocos de concreto com resíduos de borracha de pneus. Engenharia Estudo e Pesquisa, v. 6, p. 36-41, 2003.

GOVERNO DO ESTADO DE ALAGOAS (Brasil). Nota sobre Concreto Verde: Alagoas: 2012. Disponível em: <http://www.cienciaetecnologia.al.gov.br/sala-deimprensa/noticias/2011/05/concreto-verde>. Acessado em: 15 out. 2012.

ISAIA, G. C.; GASTALDINI, A. L. G. Perspectivas ambientais e econômicas do concreto com altos teores de adições minerais: um estudo de caso. Ambiente Construído, v. 4, n. 2, p. 19-30, 2004.

MEHTA, P. K.; MONTEIRO, P. J. M. CONCRETO, Microestrutura, Propriedades e Materiais. 3 ed. São Paulo IBRACON 2008, p. 665-667.

PINTO, T. P. Metodologia para a gestão diferenciada de resíduos sólidos da construção urbana. 1999. 189 f. Tese (Doutorado em Engenharia) - Escola Politécnica, Universidade de São Paulo, São Paulo, SP, 1999. 